\section{ZERTIFIZIERTE FORTBILDUNG}

IN ZUSAMMENARBEIT MIT DER BAYERISCHEN LANDESÄRZTEKAMMER Folge 155

b) für freiwillige Fortbildungszertifikate, die viele Landesärztekammern anbieten.

Die Multiple-Choice-Fragen beziehen sich auf den vorangegangenen Fortbildungsbeitrag (Seiten 38-41). Die Antworten ergeben sich z. T. aus dem Text, z. T. beruhen sie auf medizinischem Basiswissen!

Wenn Sie 70\% der Fragen richtig beantworten, erhalten Sie 2, bei 100\% 3 CME-Punkte.

Einsendeschluss: 6. Juli 2008 (www.cme-punkt.de) bzw. 20. März 2008 (Teilnahme per Brief).
MMW

Fortschritte der Medizin

CME-Herausgeber- und Review-Board:

Dr. H. J. K. Barwitz, Prof. Dr. A. Berghaus, Prof. Dr.

Dr.h.c. Th. Brandt, Prof. Dr. W. G. Daniel, Prof. Dr.

W. Eisenmenger, Prof. Dr. K. Friese, Prof. Dr. H. S.

Füessl, Prof. Dr. B. Göke, Prof. Dr. R. Gradinger,

Prof. Dr. H. Holzgreve, Prof. Dr. A. Imdahl, Prof.

Dr. K.-W. Jauch, Prof. Dr. K. Krüger, Prof. Dr. H.-J.

Möller, Prof. Dr. D. Reinhardt, Prof. Dr. Dr. h.c. Th.

Ruzicka, Prof. Dr. Ch. Stief, U. Weigeldt.

\title{
Fragen zum Thema „Der Zufallsbefund in der Praxis“
}

1. Was versteht man unter dem KnöchelArm-Index?

A Den Quotienten aus dem am Oberarm geteilt durch den am Fuß gemessenen systolischen Blutdruck.

B Den Quotienten aus dem am Fuß geteilt durch den am Oberarm gemessenen systolischen Blutdruck.

C Die Differenz zwischen dem am Oberarm und am Unterschenkel gemessenen systolischen Blutdruck.

D Das Produkt aus dem am Oberschenkel und am Unterschenkel gemessenen systolischen Blutdruck.

E Den Quotienten aus dem am Oberarm geteilt durch den am Unterschenkel bestimmten arteriellen Mitteldruck.

- 2. Sie messen einen Dopplerdruck von $260 \mathrm{mmHg}$ am Fuß bei einem Oberarmdruck an beiden Armen von $140 \mathrm{mmHg}$. Was liegt hier wahrscheinlich vor?

A Ein technischer Gerätedefekt

B Eine maligne Hypertonie

C Eine Aortenisthmusstenose

D Eine Mönckebergsche Mediasklerose

E Eine Medianekrose Erdheim-Gsell

- 3. Welcher Bereich gilt beim KnöchelArm-Index als normal?

A Werte $<0,5$

B Werte zwischen 0,5 und 0,9

C Werte zwischen 0,9 und 1,3

D Werte zwischen 1,3 und 1,9

E Werte $>1,9$

- 4. In einem „Routinelabor" stellen Sie ein erhöhtes Serum-Kalzium von $\mathbf{2 , 8} \mathrm{mmol} / \mathrm{l}$ fest. Wohin lenken Sie Ihren Blick als Nächstes?

A Serum-Bilirubin

B Leukozyten

C Serum-Albumin

D Serum-Natrium

E CRP

- 5. Was bezeichnet der in Lehrbüchern des Öfteren verwendete Ausdruck ,Stein-, Bein- und Magenpein"?

A Nierensteine, Knochenschmerzen und Magenulzera

B Blasensteine, Beinschmerzen und Völlegefühl

C Schüttelfrost („es friert Stein undBein") und Sodbrennen

D Uretersteine, Arthralgien und Reizdarm

E Fibromyalgie

- 6. Was ist der häufigste Grund für einen primären Hyperparathyreoidismus?

A Eine Hyperthyreose

B Ein Epithelkörperchenadenom

C Ein Epithelkörperchenkarzinom

D Ein Bronchialkarzinom

E Ein Rezeptordefekt

\section{Welche Befundkonstellation ist} typisch für das Löfgren-Syndrom?

A Leukozytose, Fieber, Arthritis

B Arthritis, Erythema migrans, vergrößerte Leistenlymphknoten

C Erythema nodosum, Arthritis, Hiluslymphknotenschwellungen

D Eosinophilie im Sputum, Hiluslymphknotenvergrößerung
E Endokarditis, Eosinophilie, Erythema anulare

- 8. Welche Aussage zur Sarkoidose trifft nicht zu?

A Die Sarkoidose zeigt große Spontanheilungstendenz.

B Die Sarkoidose wird oft zufällig entdeckt.

C Die Sarkoidose befällt nur die Lunge.

D Die Sarkoidose wird gelegentlich mit Steroiden behandelt.

E Die fortgeschrittenen Stadien der Sarkoidose sind durch eine restriktive Ventilationsstörung gekennzeichnet.

\section{-9. Worin besteht das histologische Korre-} lat der Sarkoidose?

A In verkäsenden Nekrosen.

B In lymphoplasmazellulären Infiltraten.

C In verkalkenden Nekrosen.

D In epitheloidzelligen Granulomen.

E In hämosiderinhaltigen Makrophagen.

- 10. Bei einem 28-jährigen beschwerdefreien Patienten, der wegen einer Einstellungsuntersuchung kommt, zeigt das Röntgenbild der Lunge vergrößerte Hiluslymphknoten. Wie gehen Sie vor?

A Bei V. a. Tuberkulose sofortige Einleitung einer Therapie mit Isoniazid, Rifampicin, Ethambutol und Pyrazinamid

B Zunächst keine Therapie, aber regelmäBige Kontrollen in jährlichem Abstand

C Verschreiben eines Bronchodilatators

D Überweisung in eine chirurgische Fachabteilung

E Einleiten einer Steroidtherapie

\section{ANTWORTFORMULAR}

Mit Einreichen dieses Fragebogens erkläre ich mich damit einverstanden, dass die angegebenen Daten zum Zweck der Teilnahmebestätigung gespeichert und bei erfolgreicher Teilnahme an den Einheitlichen Informationsverteiler (EIV) der Ärztekammern weitergegeben werden.

Wichtiger Hinweis:

Eine Auswertung ist künftig nur noch möglich, wenn Sie Ihre EFN auf dem Antwortformular angeben!

Nähere Hinweise hierzu unter:

www.cme-punkt.de/faq.html

\section{"Zufallsbefund in der Praxis“}

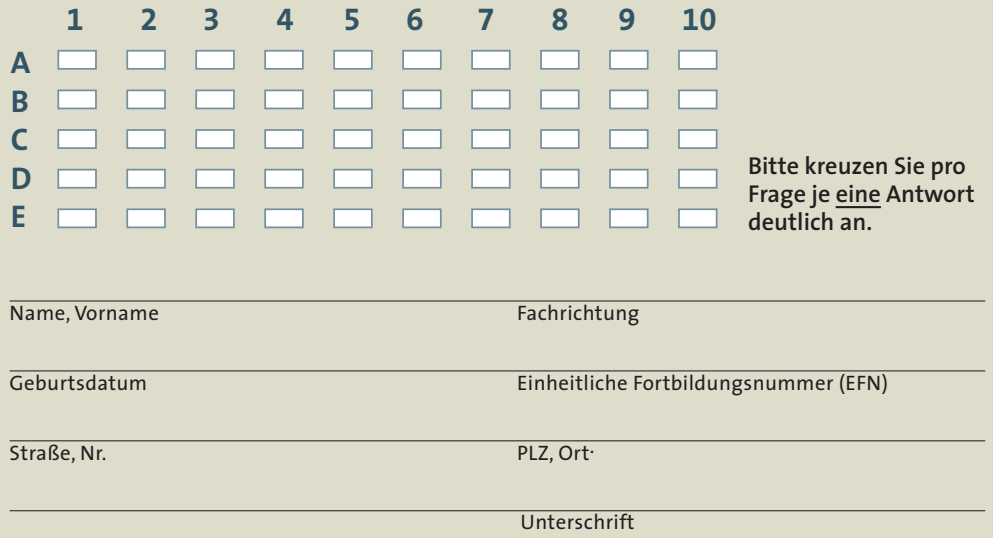

Und so kommen Sie zu lhren Punkten:

Teilnahme im Internet: unter www.cme-punkt.de. Dort führen wir für Sie ein elektronisches Punktekonto.

Teilnahme per Brief: Fragebogen ausfüllen und mit frankiertem Rückumschlag an: Urban \& Vogel GmbH CME MMW-Fortschr. Med. Postfach 81664 München 